\title{
Rational design of a nitroreductase-activatable two-photon fluorescent probe for hypoxia imaging in cell and in vivo
}

\author{
Yue Wang ${ }^{\mathrm{a}, \mathrm{d}}$, Li Zhang ${ }^{\mathrm{a}, \mathrm{d}}$, Yan Huang ${ }^{\mathrm{a}, \mathrm{b}}$, Xiaoyan Wang ${ }^{\mathrm{b}}$, Liangwei Zhang ${ }^{\mathrm{a}}$, Lingxin Chen ${ }^{\mathrm{a}, \mathrm{b}, \mathrm{c}, *}$ \\ ${ }^{a}$ CAS Key Laboratory of Coastal Environmental Processes and Ecological Remediation, Yantai Institute of Coastal Zone Research, Chinese Academy of Sciences, Yantai, \\ 264003, China \\ b School of Pharmacy, Binzhou Medical University, Yantai, 264003, China \\ ${ }^{\mathrm{c}}$ Center for Ocean Mega-Science, Chinese Academy of Sciences, Qingdao, 266071, China \\ ${ }^{\mathrm{d}}$ University of Chinese Academy of Sciences, Beijing, 100049, China
}

\section{A R T I C L E I N F O}

\section{Keywords:}

Nitroreductase detection

Fluorescent probe

Hypoxia imaging

Tumor treatment

Two-photon imaging

\begin{abstract}
A B S T R A C T
Tumor resistance is a huge challenge for tumor treatment, which may lead to tumor treatment failure. Relieving tumor resistance and improving efficacy are long-term goals for tumor treatment. Nitroreductase (NTR) is an endogenous enzyme that highly expressed in hypoxia tumors. Herein, we develop a NTR-activatable fluorescent probe, TP- $\mathrm{NO}_{2}$, for NTR detection during tumor treatment. TP- $\mathrm{NO}_{2}$ with simple synthesis steps and high yield can qualitatively and quantitatively detect NTR in a wide range $(0-20 \mu \mathrm{g} / \mathrm{mL})$ with a detection limit of $26 \mathrm{ng} /$ mL. The probe has been successfully applied for NTR detection in cells under simulated hypoxia conditions. Hyperbaric oxygen (HBO) can alleviate tumor hypoxia and reduce NTR concentration. We pre-evaluate the effect of tumor treatment by NTR imaging. And the results demonstrate that HBO-assistant chemotherapy can effectively treat tumor cells. We further apply $\mathrm{TP}-\mathrm{NO}_{2}$ for NTR detection in A549 and cis-dichlorodiamineplatinum(II) (DDP)-resistant A549 (A549/DDP) xenograft nude mice, and we choose NTR as an indicator to pre-evaluate the treatment efficacy of malignant tumors. With the adjuvant therapy of HBO, chemotherapeutic drugs gemcitabine and carboplatin can effectively treat A549 and A549/DDP xenograft. These applications provide us a novel perspective for NTR imaging.
\end{abstract}

\section{Introduction}

Hypoxia has been considered as an inherent feature of solid tumor, whereby the oxygen $\left(\mathrm{O}_{2}\right)$ concentration ranges from $4.0 \%$ to $0 \%$. [1] Tumor hypoxia has been known as a pathophysiological consequence of deteriorating microenvironment, and it is mainly derived from the rapid and exaggerated growth of tumor cells [2]. Hypoxia can lead to structures, functions and diffusion conditions of tumors disturbed, and it plays significant roles in tumor invasion, metastasis and drug resistance [3]. Researchers report that hypoxia causes many tumor-associated genes overexpress, especially hypoxia inducible factors $1 \alpha$ (HIF-1 $\alpha$ ) and HIF-mediated genes $[4,5,48]$. Within the hypoxic tumor microenvironment, HIF-1 $\alpha$ promotes angiogenesis, metabolic adaptation, and other key aspects of tumor progression, which results in deteriorating tumor hypoxic microenvironment and abnormal microvessels. [5] These a series of behaviors limit the perfusion of cytotoxic chemotherapeutic drugs, and further reduce the efficacy of chemotherapeutic drugs as well as lead to tumor resistance [5]. Hyperbaric oxygen (HBO) can alleviate tumor hypoxia by increasing oxygen partial pressure, and it has been used in many studies for seeking to reverse hypoxic conditions of tumor [6]. HBO can significantly increase intracellular oxygen partial pressure to overcome hypoxia-induced chemotherapy and radiotherapy resistance, as well as improve drug treatment efficacy. [7-9] Thus HBO-assistant chemotherapy may be a promising strategy for malignant tumor treatment. And powerful tools are needed urgently for assessing the therapeutic effect of malignant tumors.

Nitroreductase (NTR) is an endogenous enzyme that overexpressed in hypoxic tumors, and the concentration of NTR is directly concerned to the degree of hypoxia. [10] NTR is seen as an indicator of highly invasive diseases in various hypoxic tumors and NTR overexpression plays important roles in tumor invasion, progression and angiogenesis [11]. Further studies show that the hypoxic status of solid tumors is closely related to the process of tumor progression [12]. Therefore, NTR

\footnotetext{
* Corresponding author at: CAS Key Laboratory of Coastal Environmental Processes and Ecological Remediation, Yantai Institute of Coastal Zone Research, Chinese Academy of Sciences, Yantai, 264003, China.

E-mail address: 1xchen@yic.ac.cn (L. Chen).
} 
can be selected as a biomarker and the hypoxia degree of solid tumor can be assessed by evaluating the NTR level [13]. NTR is a kind of flavin-dependent enzyme, which can reduce nitroaromatic compounds and nitroheterocyclic derivatives to primary amines through ping-pong mechanism with two electrons transferring, and nicotinamide adenine dinucleotide hydrogen (NADH) is used as the electron donor [14]. Inspired by this reaction, designing potential molecular tools for tumor hypoxia detection are needed urgently.

Traditional hypoxia detection methods include positron emission tomography technique, $\mathrm{pO}_{2}$ electrodes, magnetic resonance imaging and multispectral optoacoustic tomography (MSOT) imaging. [15-19] However, these methods usually require complex sample pretreatment, expensive consumption, destruction of tissues and cells. NTR-activatable fluorescent probe technology has received great attentions for its advantages such as less invasiveness, highly selectivity, rapidly response, highly spatial and temporal resolution, real-time and in situ detection. [20,46,47] Recently, two-photon fluorescent probes using two near-infrared (NIR) photons as the excitation source have aroused our great attention. Comparing to traditional one-photon fluorescent probes, two-photon fluorescent probes can achieve higher spatial and temporal resolution, deeper tissue imaging depth and longer observation time $[21,51,52]$. However, there are fewer two-photon fluorescent probes for NTR detection available so far, and the developed twophoton fluorescent probes usually have short fluorescence emission [21-25]. Thus powerful two-photon fluorescent probes with longer fluorescence emission wavelength are required urgently for NTR detection in tumor.

Here, we designed a NTR-activatable fluorescent probe TP- $\mathrm{NO}_{2}$ with long fluorescence emission for NTR detection. TP- $\mathrm{NO}_{2}$ was designed based on a two-photon fluorophore TP-OH and a responsive group $p$ nitrobenzene. Our probe had highly selectivity and sensitivity for NTR detection. Using TP-NO $\mathrm{N}_{2}$, we can explore the relationship between NTR concentration and the degree of hypoxia. We evaluated the therapeutic effect of HBO-assistant chemotherapy in A549 cells and DDP-resistant A549 (A549/DDP) cells through NTR detection. We also performed apoptosis detection, mitochondrial membrane potential analysis, transmission electron microscopy experiments to confirm the treatment effect. In addition, we applied $\mathrm{TP}-\mathrm{NO}_{2}$ for NTR detection in the nude mice models that bearing A549 and A549/DDP xenograft for preliminary assessment of treatment efficacy. As far as we known, TP- $\mathrm{NO}_{2}$ was the first fluorescence imaging tool for NTR detection in the process of HBO-assistant chemotherapy for tumor treatment.

\section{Experimental section}

\subsection{Cell culture}

Human lung carcinoma (A549) cells and human neuroblastoma (SH-SY5Y) cells were purchased from the Committee on Type Culture Collection of Chinese Academy of Sciences (Shanghai, China). A549 cells were cultured with DMEM supplemented with $10 \%$ FBS. SH-SY5Y cells were cultured with RPMI-1640 supplemented with $10 \%$ FBS. All cells were incubated at $37^{\circ} \mathrm{C}$ under a humidified atmosphere containing $5 \% \mathrm{CO}_{2}$. The cells were passaged by scraping and seeding on $20 \mathrm{~mm}$ Petri-dishes according to the instructions from the manufacturer. A multi gas incubator (Sanyo) was used for producing 1-21\% $\mathrm{O}_{2}$ concentration by means of $\mathrm{N}_{2}$ substitution. And $0.1 \% \mathrm{O}_{2}$ concentration was generated with an AnaeroPack ${ }^{\mathrm{TM}}$ (Mitsubishi Gas Chemical Campany, Co. Inc., Japan).

\subsection{Confocal imaging}

Cells were plated on Petri-dishes $(\Phi=20 \mathrm{~mm})$ and allowed to adhere for $24 \mathrm{~h}$ before imaging. The probe was added to the culture plates which were filled with $1 \mathrm{~mL}$ fresh complete medium. One-photon fluorescent images were acquired on an Olympus Fluo View FV1000 confocal laser-scanning microscope (Japan). The collection wavelength was $\lambda_{\text {em }}=530-630 \mathrm{~nm}\left(\lambda_{\text {ex }}=440 \mathrm{~nm}\right)$. The two-photon fluorescent images were collected using a two-photon laser confocal microscope (Zeiss LSM 880). The collection wavelength was $\lambda_{\mathrm{em}}=530-630 \mathrm{~nm}$ $\left(\lambda_{\text {ex }}=840 \mathrm{~nm}\right)$.

\subsection{Establishment of the A549 and A549/DDP transplanted tumor nude mice}

5-week-old specific pathogen free nude mice were provided by Changzhou Cavens Lab Animal Co. Ltd. The mice were housed in individual ventilated cages, and a SPF laboratory diet and water were acquired freely. Mice were group-housed on a 12:12 light-dark cycle. 2 $\times 10^{6}$ cells were suspended in media and implanted subcutaneously into nude mice. A549 and A549/DDP xenografts were established in nude mice until the tumor volumes typically reached to about 200 $\mathrm{mm}^{3}$. All experiments were performed in accordance with the guidelines established by the Committee of Animal Research Policy of Binzhou Medical University.

\subsection{Mice imaging in vivo}

A Bruker In-vivo Imaging System was employed to imaging tumor bearing nude mice. The excitation and emission wavelengths were chosen as $465 \mathrm{~nm}$ and $560 \mathrm{~nm}$. The mice were anesthetized prior to injection and during imaging. After in vivo imaging, the organs (lung, heart, liver, kidney and spleen) and tumors were excised to perform $e x$ vivo imaging.

\subsection{Synthesis of compounds}

Compounds were synthesized according to the general procedure and characterization details were described in the Supporting Information.

Synthesis of compound TP-NO . Compound TP-OH (0.0342 g, 0.1 $\mathrm{mmol})$ and $\mathrm{K}_{2} \mathrm{CO}_{3}(0.0691 \mathrm{~g}, 0.5 \mathrm{mmol})$ were dissolved in DMF $(30 \mathrm{~mL})$ for $30 \mathrm{~min}$, then 4-nitrobenzyl bromide $(0.0432 \mathrm{~g}, 0.2 \mathrm{mmol})$ was added overnight. After concentrated, the obtained crude product was purified by silica column chromatography (200-300 mesh) to afford an orange product $(0.73 \mathrm{~g}, 73.5 \%) .{ }^{1} \mathrm{H}$ NMR (500 MHz, DMSO-D6) $\delta$ (ppm): 0.82-0.93 (m, $3 \mathrm{H}), 1.29$ (s, $6 \mathrm{H}), 3.84-4.02$ (d, $2 \mathrm{H}), 4.44-4.70$ (s, $2 \mathrm{H}), 7.03-7.15$ (s, $1 \mathrm{H}), 7.37-7.45$ (m, $1 \mathrm{H}), 7.48-7.56$ (d, $2 \mathrm{H})$, 7.57-7.70 (m, 2 H), 7.70-7.77 (t, 2 H), 7.77-7.97 (m, 4 H), 7.98-8.09 (s, $1 \mathrm{H}$ ), 8.35-8.46 (s, $3 \mathrm{H}$ ). LC-MS (API-ES): $m / z \mathrm{C}_{31} \mathrm{H}_{29} \mathrm{~N}_{2} \mathrm{O}_{3}{ }^{+}$Calcd 477.57, found $\left[\mathrm{M}^{+}\right]$477.43.

\section{Results and discussion}

\subsection{Design and synthesis of $\mathrm{TP}-\mathrm{NO}_{2}$}

For NTR detection, many one-photon fluorescent probes have been developed. $[4,10,26,27]$ However, two-photon fluorescent probes are currently rare. Herein, we designed a two-photon fluorescent probe for NTR detection. We selected two-photon fluorophore TP-OH as fluorescence reporter [28]. After fluorescence reporting unit was selected, we linked $p$-nitrobenzene, an classical identification unit for NTR detection, to the fluorophore through an ether linkage (Scheme 1). The $p$ nitrobenzene group was known to decrease fluorescence emission via a donor excited photo-induced electron transfer ( $d$-PET) process. As expected, probe TP- $\mathrm{NO}_{2}$ showed no fluorescence emission due to $p$-nitrobenzene quenched the fluorescence of TP- $\mathrm{NO}_{2}$. After reaction with NTR, $p$-nitrobenzene unit was reduced to aminobenzene group with $\mathrm{NADH}$ as a cofactor. Then, TP- $\mathrm{NO}_{2}$ experienced 1, 6-rearrangement elimination reaction to give a turn-on fluorescence signal at $580 \mathrm{~nm}$, which ascribed to the PET suppression mechanism. And the reaction mechanism was confirmed using HPLC (Figure S13). Compared to the 

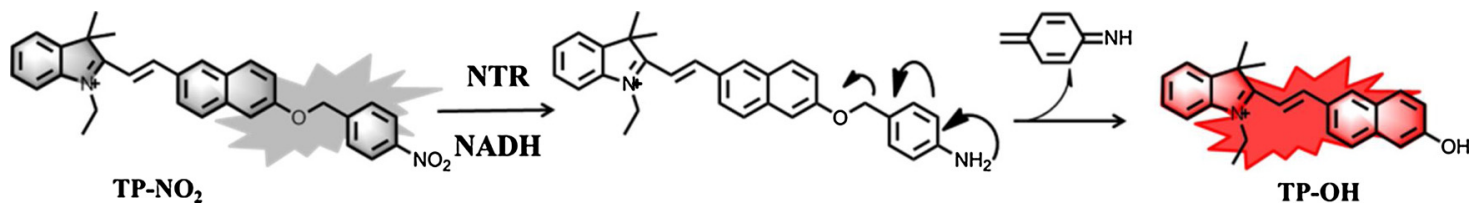

Scheme 1. Reaction mechanism of TP- $\mathrm{NO}_{2}$ for NTR detection.

developed two-photon fluorescent probe, probe $\mathrm{TP}^{-\mathrm{NO}_{2}}$ showed a large two-photon action cross section $(\delta)$ value of $126 \mathrm{GM}$ at $840 \mathrm{~nm}$ (Figure S15), good selectivity and sensitivity with a low detection limit of 26 $\mathrm{ng} / \mathrm{ml}$, high molar absorption coefficient, high yield as well as long fluorescence emission wavelength that can avoid autofluorescence from organisms (Table S1). [21-25] The detailed synthesized steps were shown in Scheme S1.

\subsection{Spectral properties of probe $\mathrm{TP}-\mathrm{NO}_{2}$ towards $\mathrm{NTR}$}

The spectral properties of TP- $\mathrm{NO}_{2}$ were detected in $10 \mathrm{mM}$ HEPES buffer (simulated physiological conditions, $\mathrm{pH}$ 7.4) with $0.5 \mathrm{mM} \mathrm{NADH}$ as cofactor. Our probe showed sensitive spectral responses towards NTR $(0-20 \mu \mathrm{g} / \mathrm{ml})$ (Fig. 1a). TP- $\mathrm{NO}_{2}$ showed faint absorption in the absence of NTR. Upon NTR was added, increased absorption spectrum can be observed at $450 \mathrm{~nm}\left(\varepsilon=8.2 \times 10^{3}, \phi=0.001\right)$. Then, the fluorescence spectrums were detected (Fig. 1b). TP- $\mathrm{NO}_{2}$ exhibited no fluorescence emission in the absence of NTR. Strong fluorescence emission at $580 \mathrm{~nm}$ can be observed upon NTR was added ( $\left.\varepsilon=5.7 \times 10^{4}, \phi=0.049\right)$. There was a good linear relationship between the fluorescence intensity and NTR concentration $(0-20 \mu \mathrm{g} / \mathrm{ml})$. The linear regression equation was $F_{\lambda \mathrm{ex} / \mathrm{em}(450 / 580 \mathrm{~nm})}=7.916 \times 10^{4} \times[\mathrm{NTR}]+4.330 \times 10^{4}$ with $\mathrm{r}$ $=0.9925$ (Figure S1b). The limit of detection was determined to be 26 $\mathrm{ng} / \mathrm{mL}(3 \sigma / \kappa)$ indicated that $\mathrm{TP}-\mathrm{NO}_{2}$ had a high sensitivity for NTR detection.

The reaction kinetic was a critical parameter for applications of the probe. Then the reaction kinetic of TP-NO $\mathrm{NO}_{2}$ towards NTR was elucidated in the presence of NADH. As shown in Fig. 1c, the reaction rate increased with the concentration of $\mathrm{TP}-\mathrm{NO}_{2}$ increased. In addition, the kinetic parameters of the NTR-catalyzed cleavage reaction were also detected. Fig. 1c showed a Lineweaver-Burk double-reciprocal plot of $1 / \mathrm{V}$ ( $\mathrm{V}$ was the initial reaction rate) versus the reciprocal of the probe $\mathrm{TP}-\mathrm{NO}_{2}$ concentration. The equation was described as: $\mathrm{V}=\mathrm{V}_{\max }$ [probe] / $\left(\mathrm{K}_{\mathrm{m}}+\right.$ [probe]), where $\mathrm{V}$ was the reaction rate, [probe] was the probe concentration, and $\mathrm{K}_{\mathrm{m}}$ was the Michaelis constant. According to the equation, the calculated values of the $\mathrm{K}_{\mathrm{m}}$ and $\mathrm{V}_{\max }$ were determined to be $46.82 \mu \mathrm{M}$ and $0.13 \mu \mathrm{M} / \mathrm{S}$ respectively.

\subsection{NTR detection in hypoxia cells}

Encouraged by the good spectral response of TP- $\mathrm{NO}_{2}$ towards NTR in Fig. 1, we further performed NTR detection in living cells. Before applied for cells imaging, MTT assays were performed for evaluating the cytotoxicity of $\mathrm{TP}-\mathrm{NO}_{2}$. As shown in Figure S3, the high cells viability illustrated that our probe displayed low cytotoxicity towards living cells. Then, the fluorescence imaging of NTR in living cells was performed by laser scanning confocal microscope. As shown in Fig. 2, we selected A549 cells and SH-SY5Y cells as cell models for NTR imaging, and the cells were divided into six groups with different oxygen concentration ( $21 \%, 10 \%, 5 \%, 3 \%, 1 \%$ and $0.1 \%$ ) for $6 \mathrm{~h}$. All the cells were incubated with TP- $\mathrm{NO}_{2}(10 \mu \mathrm{M})$ for $25 \mathrm{~min}$ before imaging. The detailed cell processing processes were shown in experimental section. As shown in Fig. 2a, our probe showed faint fluorescence under normoxic condition $\left(21 \% \mathrm{O}_{2}\right)$, which indicated that the level of NTR was low under normal condition. The fluorescence intensities increased gradually with the concentration of $\mathrm{O}_{2}$ decreased, which implied that the level of NTR increased. Thus, the degree of hypoxia can be evaluated by NTR detection. [10] Flow cytometry analysis has been considered to be a high-throughput assay technology, and it has been widely used for analysis of large number of samples. Then, we performed flow cytometry analysis to confirm the fluorescence imaging results (Fig. 2d). The results from flow cytometry analysis were consistent with that from laser confocal imaging, and the fluorescence intensity increased with the $\mathrm{O}_{2}$ concentration decreased. Corresponding fluorescence intensity analysis of Fig. 2a and d were shown in Fig. $2 f$ and h. Dicoumarin was a well-known inhibitor for NTR. $[4,48]$ Then we incubated cells with $100 \mu \mathrm{M}$ dicoumarin to inhibit NTR for $2 \mathrm{~h}$. As shown in Fig. 2b, cells showed extremely weak fluorescence signals after incubated with dicoumarin, which further confirmed the selectivity of TP- $\mathrm{NO}_{2}$ for NTR. And we also captured faint fluorescence signals using flow cytometry (Fig. 2e). The fluorescence intensity analysis of Fig. 2b and e were shown in Fig. $2 \mathrm{~g}$ and i. These results indicated that our probe $\mathrm{TP}-\mathrm{NO}_{2}$ can be applied for hypoxia detection in cells via endogenous NTR detection. We also performed NTR detection using two-photon confocal microscope in Fig. 2c, and the corresponding fluorescence intensity analysis was shown in Fig. $2 \mathrm{j}$ and $2 \mathrm{k}$. Using twophoton confocal microscope, we can capture bright fluorescence in hypoxia conditions. After treated with dicoumarin, the fluorescence signal was decreased. Thus, the results from one-photon confocal microscope and two-photon confocal microscope were consistent well.

\subsection{NTR detection during the process of tumor cell treatment}

Hypoxia is a typical feature of tumors. It has been reported that tumor treatment while relieving tumor hypoxia may improve the efficacy of radiotherapy, chemotherapy and immunotherapy [29]. Then we
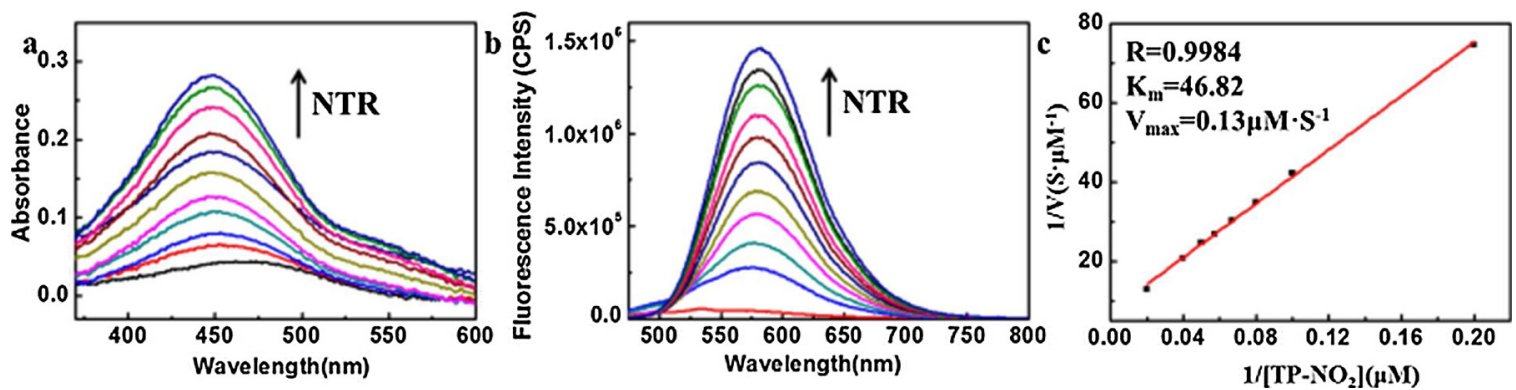

Fig. 1. Spectral properties of TP- $\mathrm{NO}_{2}$ towards NTR. (a) Absorbance spectra of $\mathrm{TP}^{-\mathrm{NO}_{2}}(10 \mu \mathrm{M})$ towards $\mathrm{NTR}(0-20 \mu \mathrm{g} / \mathrm{ml})$. (b) Fluorescence spectra of TP-NO${ }_{2}(10$ $\mu \mathrm{M})$ towards NTR $(0-20 \mu \mathrm{g} / \mathrm{ml}) . \lambda_{\mathrm{ex}}=450 \mathrm{~nm}$. (c) Lineweaver-Burk plot for enzyme-catalyzed reaction. TP- $\mathrm{NO}_{2}(5,10,12.5,15,17.5,20,25,50 \mu \mathrm{M})$. 

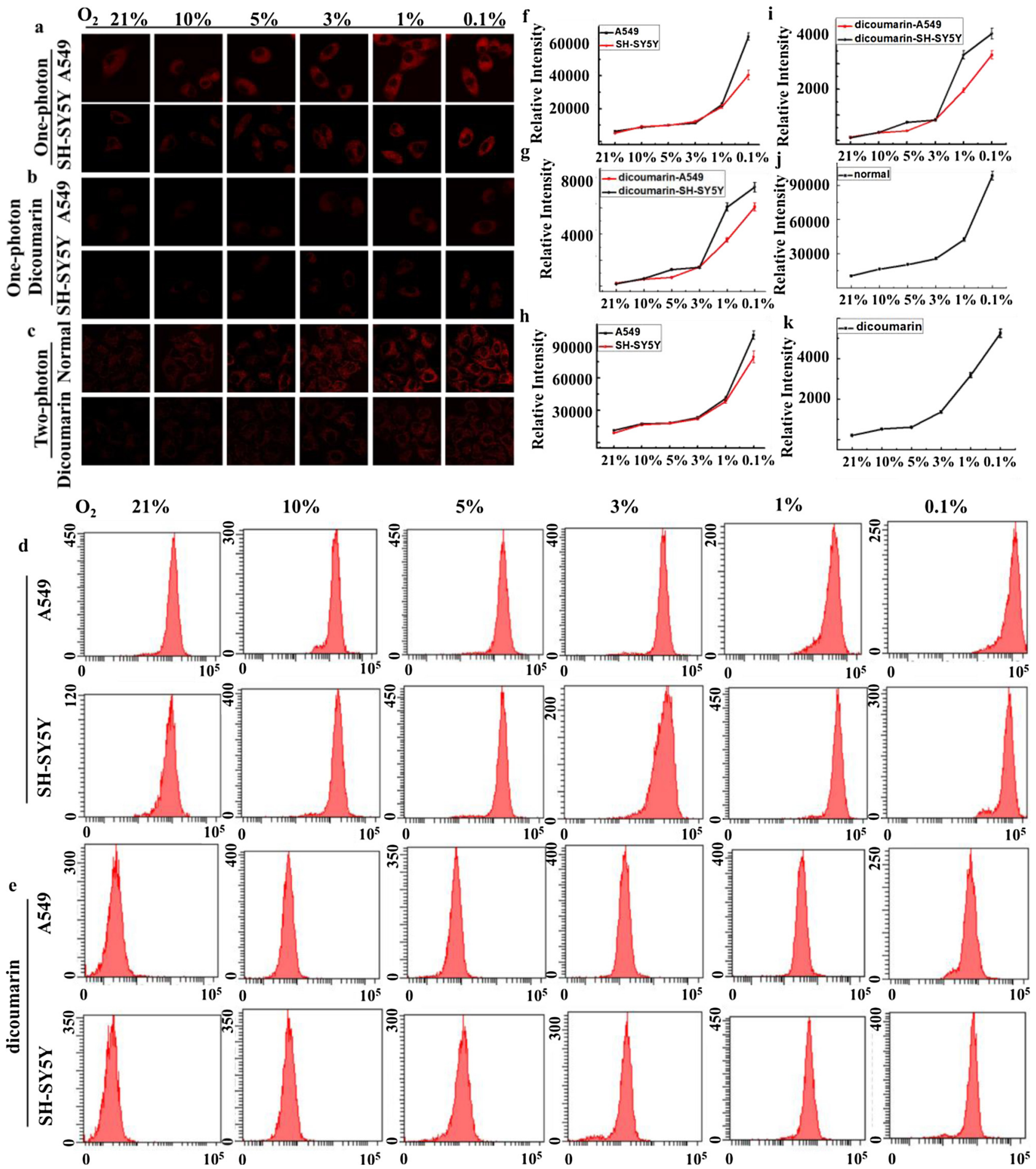

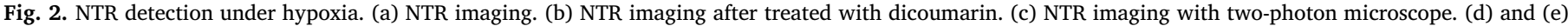

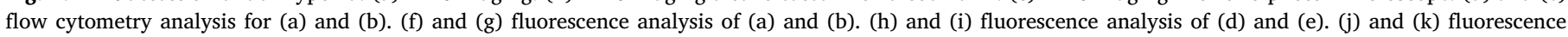
intensities analysis of cells under normal and dicoumarin conditions in (c).

attempted to investigate the auxiliary treatment effect of $\mathrm{HBO}$ during chemotherapy. NTR is an endogenous enzyme and closely related to oxygen concentration. The results of cell experiments indicated that the hypoxia degree of tumor cells can be evaluated by NTR detection $[4,30,48]$. Since our probe TP- $\mathrm{NO}_{2}$ had been used for NTR detection successfully under different $\mathrm{O}_{2}$ concentrations, we attempted to evaluate the NTR concentration fluctuations during the process of tumor treatment. A549 and SH-SY5Y cells were selected as cell models and the cells in Fig. 3a were divided into five groups. The detailed cell processing processes were shown in Supporting Information. The cells in the control group were manipulated under normoxic conditions, and they showed weak fluorescence signals. Cells in the next group were treated under hypoxia $\left(0.1 \% \mathrm{O}_{2}\right)$ for $6 \mathrm{~h}$, and intense fluorescence signals were recorded. Next, we incubated cells under $\mathrm{HBO}\left(60 \% \mathrm{O}_{2}\right)$ for $6 \mathrm{~h}$, and decreased fluorescence intensity can be observed. Gemcitabine and carboplatin have been widely used as chemotherapeutic drug for tumor treatment $[31,32,49]$. Carboplatin can cross-link to DNA and inhibit replication and transcription of tumor cells through forming 


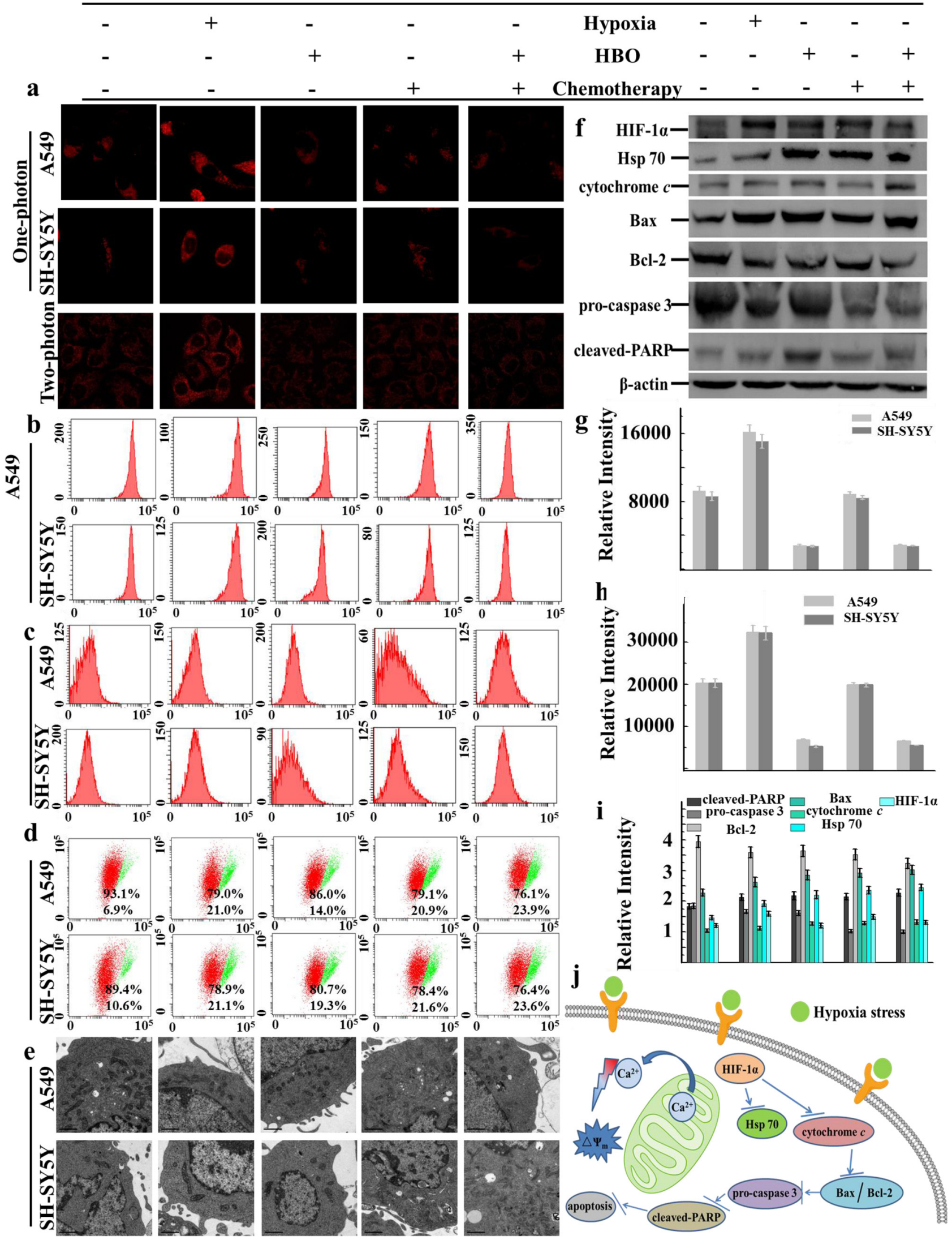

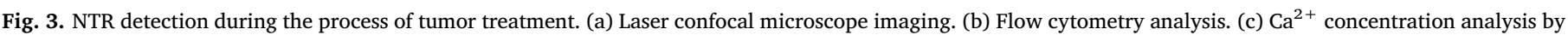

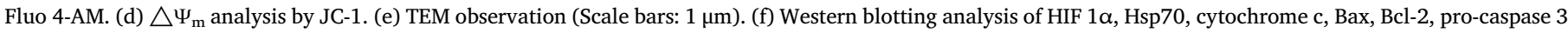

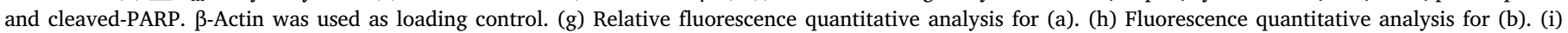
Quantitative analysis for (f). (j) Signal transduction pathways. The experiments data were shown as mean ( \pm s.d.) ( $n=7$ ). 
intra- or interstrand adducts [32,49]. Gemcitabine can promote cell apoptosis [31]. Then we selected gemcitabine and carboplatin (G/C) as the chemotherapeutic drugs for tumor cell therapy. The cells in the chemotherapy group were incubated with G/C for $1 \mathrm{~h}[32,49]$. And the changes in fluorescence signal were not obvious. Studies had shown that hypoxia can increase tumor resistance and increasing oxygen concentration can improve tumor treatment efficacy [33]. Thus, we maintained tumor cells at $\mathrm{HBO}$ condition for $6 \mathrm{~h}$ and then the cells were incubated with G/C for $1 \mathrm{~h}$. We can capture achy fluorescence signals in the cells, which indicated that the intracellular NTR concentration decreased with $\mathrm{O}_{2}$ concentration increased. The results demonstrated that we can evaluate the treatment effect through NTR detection during HBO-assistant chemotherapy. We further performed fluorescence imaging in A549 cells using two-photon confocal microscope. And the results from two-photon confocal microscope were consistent well with that from one-photon confocal microscope. Corresponding quantitative analysis was shown in Fig. 3g. We also performed flow cytometry analysis to confirm the fluorescence imaging results (Fig. 3b). Corresponding quantitative analysis was shown in Fig. $3 \mathrm{~h}$, and the results from laser confocal microscope imaging and flow cytometry analysis were consistent well. These results demonstrated that $\mathrm{TP}-\mathrm{NO}_{2}$ can be used for oxygen assessment during HBO-assistant chemotherapy and further evaluating the treatment efficacy.

Next, we evaluated the therapy efficacy of HBO-assistant chemotherapy through traditional cell damage detection. Calcium ion $\left(\mathrm{Ca}^{2+}\right)$ is one of the most important second messengers. Cell damage will cause $\mathrm{Ca}^{2+}$ stores in the mitochondria flow out into the cytoplasm and accumulate $[34,35]$. We initially assessed cell damage using Fluo 4$\mathrm{AM}$ (Fig. 3c). $\mathrm{Ca}^{2+}$ concentration was highest in cells that treated with HBO-assistant chemotherapy, which demonstrated that the cell damage was most severe in this group. The fluorescence quantitative analyses of $\mathrm{Ca}^{2+}$ concentrations were shown in Figure S6. Mitochondrial $\mathrm{Ca}^{2+}$ abnormal efflux can cause $\triangle \Psi_{\mathrm{m}}$ collapse and directly lead to cell apoptosis. Then the $\triangle \Psi_{\mathrm{m}}$ was detected by JC-1 to confirm the cell damage (Fig. 3d). And the results were consistent with the results from $\mathrm{Ca}^{2+}$ detection. We further observed the cell morphology by transmission electron microscopy (TEM) to evaluate the cell damage. As shown in Fig. 3e, we observed continuous membrane structures and regular organelle structures in the control group. However, the organelle structures had different degrees of abnormalities in different treatment groups. We can observe the membrane structures gradually turned to vague, mitochondrial were swollen, mitochondrial ridge became blurred and the number of vacuoles increased in the experimental groups. It was worth noting that the cell damage was the most severe in the HBO-assistant chemotherapy group, indicating that the HBO-assistant chemotherapy group had the best therapeutic effect. We further performed western blot analysis to explore the signal transduction pathway in the process of tumor cell treatment for evaluating cell damage (Fig. 3f). HIF-1 $\alpha$ is a high expression factor in tumor cells, which has been considered as an important target for tumor treatment $[36,37]$. We analyzed the expression levels of HIF-1 $\alpha$ in A549 cells. We found that the expression of HIF-1 $\alpha$ in control group was low, while its expression in hypoxia treatment group was the highest. Heat shock protein 70 (Hsp70) is a stress protein which can protect cells from adverse injure. The expression of Hsp70 was increased with the cell damage worsened, and the expression of Hsp70 under hypoxia was much higher than that under normoxia. Cytochrome $c$, a positively charged protein which acts as a hydrogen carrier in the electronic transmission chain, is an apoptotic mediator capable of activating apoptotic executor cleaved-caspase 3 . Once the mitochondrial membrane potential collapse, it can be released from the mitochondria into cytoplasm [38]. As shown in Fig. 3f, the expression of cytochrome $c$ was increased with the cell damage increase. Cytochrome $c$ was also an effector for downstream signal path: Bax, Bcl-2 and poly(ADP-ribose) polymerase (PARP) and caspase $3[39,40]$. The proteins Bax, Bcl-2, PARP and caspase 3 were detected, and expression of cleaved-caspase 3 and cleaved-PARP as well as the ratio of Bax and Bcl-2 were increased with the increased cell damage. Corresponding protein quantification analysis was shown in Fig. 3i. The results from traditional cell damage detection were consistent with that from efficacy assessment of TP- $\mathrm{NO}_{2}$. Thus we can pre-evaluate the therapeutic effect of HBO-assistant chemotherapy by NTR detection using TP- $\mathrm{NO}_{2}$.

Here, we emphasized that HBO-assistant chemotherapy can indeed help to kill tumor cells and improve the treatment effect. The concentration of NTR was decreased in the group that treated with HBOassistant chemotherapy. The expression of protective protein Hsp70 was increased to protect cells from damage. The large amount of $\mathrm{Ca}^{2+}$ would outflow from the damaged mitochondria to the cytoplasm, and led to the $\triangle \Psi_{\mathrm{m}}$ collapse. Then the cytochrome $c$ was released to cytoplasm from damaged mitochondria, which would further up-regulate the ratio of Bax/Bcl-2 and activate the apoptotic executor cleavedcaspase 3 as well as led to the PARP in nucleus cleaved. And the protein signal transduction mechanism during the process of tumor treatment was shown in Fig. 3j. The cell damages in the group that treated with HBO-assistant chemotherapy were much severer than that treated only HBO or chemotherapy. Thus we supposed that the combination therapy of HBO-assistant chemotherapy might be a powerful strategy for tumor treatment.

\subsection{NTR detection in A549 and A549/DDP cell line during tumor treatment}

cis-Dichlorodiamineplatinum(II) (DDP) is a commonly adopted chemotherapy drug and studies have shown that long-term drug treatment leads to DDP-resistance [41,42]. Based on the results that HBO can improve the treatment effect of tumor cells, we conducted additional experiments to explore whether HBO-assistant chemotherapy can effectively treat tumor cells. We used the A549 cell line and DDP-resistant A549 cell line (A549/DDP) as the cell models. The A549/DDP cells were obtained as described in Supporting Information. Then the cell model, A549/DDP cell line, was confirmed using MTT experiments. As shown in Figure S8, A549/DDP cell line had a higher $\mathrm{IC}_{50}$ value $(20.04 \mu \mathrm{g} / \mathrm{mL})$ than A549 cell line $(1.58 \mu \mathrm{g} / \mathrm{mL})$. We then performed NTR detection during the process of tumor treatment with G/C and HBO. As shown in Fig. 4a, we observed visible fluorescence signals in the control group whether in A549 or A549/DDP cells. Then, the cells were treated with chemotherapeutic drugs G/C and HBO, and faint fluorescence signals were captured. According to these results, we preliminarily deduced that HBO-assistant chemotherapy can effectively treat A549/DDP cells, and the therapeutic effect of A549 cell line was better than A549/DDP cell line. Corresponding fluorescence quantitative analysis was shown in Fig. 4f. The results from confocal imaging were further confirmed by flow cytometry analysis, and the results were shown in Fig. 4b. Corresponding fluorescence quantitative analysis was shown in Fig. 4g. The results from confocal imaging and flow cytometry analysis were consistent well.

Then the cell damages of A549 and A549/DDP cells in different groups were detected. First of all, the degrees of cell damage were detected using Annexin V/7-AAD Apoptosis Detection Kit (Fig. 4c). The cell damage was most serious in the group that treated with HBO-assistant chemotherapy. Thus HBO-assistant chemotherapy can effectively treat tumor cells. Comparing A549 cell line and A549/DDP cell line, the cell damage was much severer in A549 cell line than A549/ DDP cell line. Then the $\triangle \Psi_{\mathrm{m}}$ was further detected using JC-1 (Fig. 4d). The $\triangle \Psi_{\mathrm{m}}$ was lowest in the group that treated with HBO-associated chemotherapy. In addition, the fluctuations of the $\mathrm{Ca}^{2+}$ were also detected by Fluo 4-AM using flow cytometry (Fig. 4e). The $\mathrm{Ca}^{2+}$ concentration was highest in the cells that treated with HBO-assistant chemotherapy whether in A549 or A549/DDP cells. The fluorescence quantitative analysis of $\mathrm{Ca}^{2+}$ was shown in Fig. 4h. The experimental results from cell damage detection were consistent well, which confirmed the hypothesis that HBO-assistant chemotherapy can effectively 


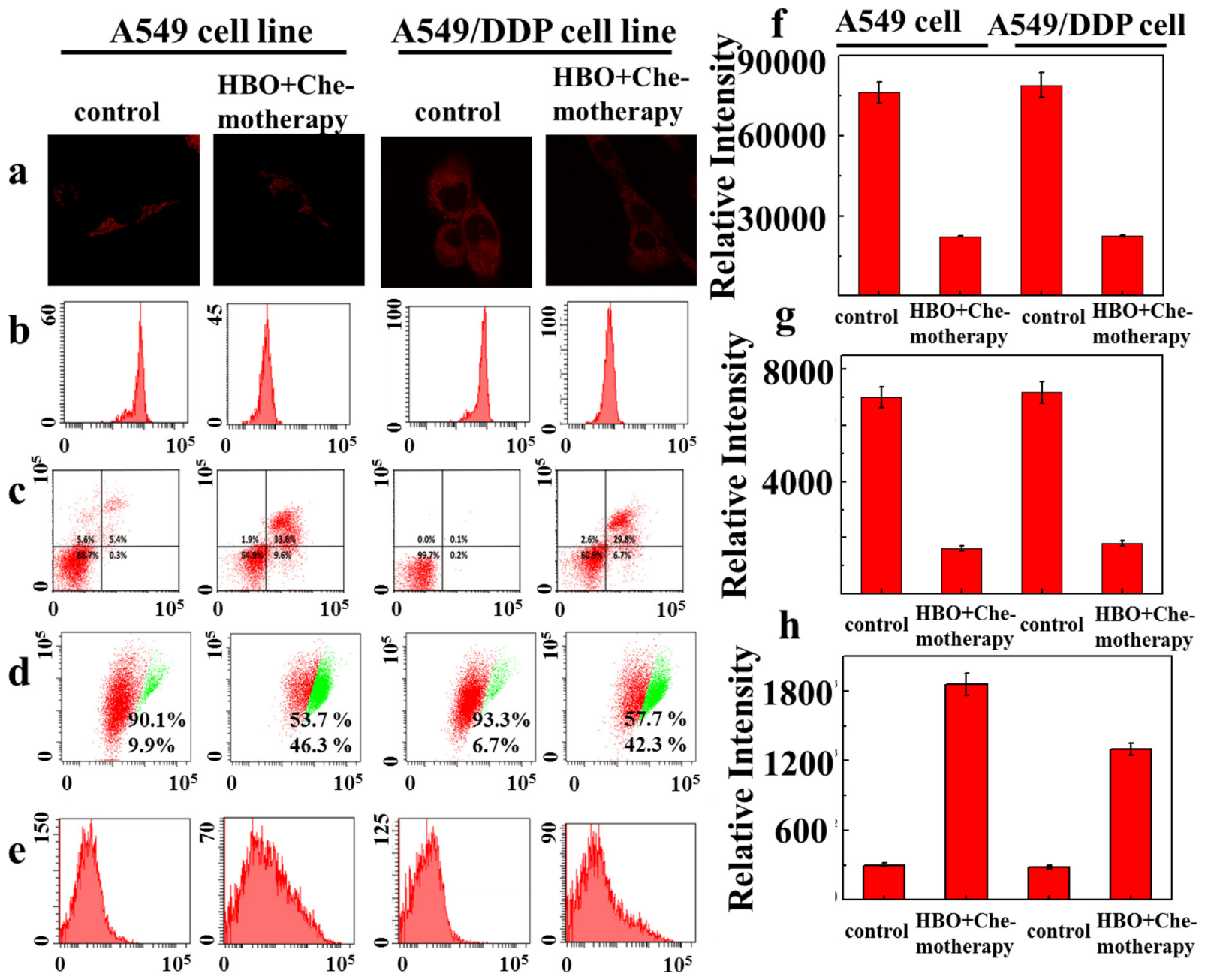

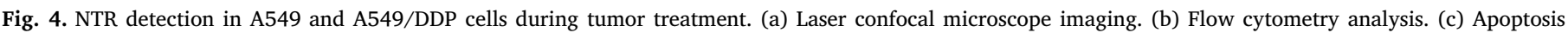

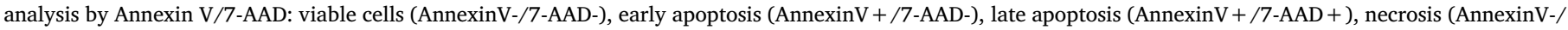

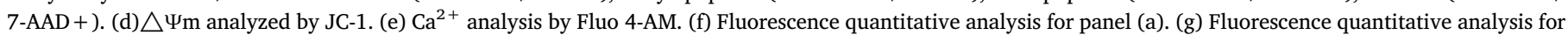
panel (b). (h) Fluorescence quantitative analysis for panel (e).

treat A549 and A549/DDP cells. Furthermore, during the process of tumor treatment with HBO-assistant chemotherapy, the concentration of NTR was decreased and can reflect the therapeutic effect. These applications made our probe a promising tool for clinical surgical preassessment of tumor treatment.

\subsection{Therapy efficacy of HBO-assistant chemotherapy in A549 xenografts mice}

Encouraged by the results that HBO-assistant chemotherapy can effectively induce tumor cell apoptosis and can effectively treat tumor cells, we then evaluated the therapy efficacy of HBO-assistant chemotherapy in A549 xenografts mice. A549 xenografts were established in nude mice until tumor volume typically reached approximately to $200 \mathrm{~mm}^{3}$ [43]. Next, tumor-bearing nude mice were divided into two groups. The mice in HBO-assistant chemotherapy group were exposed to $80 \%$ oxygen every day (five times per week) for $60 \mathrm{~min}$ and given $\mathrm{G}$ / C biweekly for 28 days (Fig. 5 details seen SI) [32,44,49,50]. Then the NTR concentrations were detected using TP- $\mathrm{NO}_{2}$, and the fluorescence signal acquisition was continued for $30 \mathrm{~min}$. TP- $\mathrm{NO}_{2}(1 \mu \mathrm{M}, 50 \mu \mathrm{L}$ in 1:99 DMSO/saline v/v) was intratumorally injected for NTR detection. As shown in Fig. 5a, bright fluorescence signals were observed in the control group, which indicated that NTR concentration in the control group was high. The concentration of NTR in the group that treated with HBO-assistant chemotherapy was decreased dramatically. Then the organs (including tumor, heart, liver, spleen, lung and kidney) were obtained for fluorescence imaging. As shown in Fig. 5d, we only observed fluorescent signals in tumor tissues. The corresponding fluorescence quantitative analysis of Fig. $5 \mathrm{a}$ and d were shown in Fig. $5 \mathrm{e}$ and $\mathrm{f}$. The fluorescent signals in the tumor area can last for at least $30 \mathrm{~min}$, and there was no fluorescent signal in the non-tumor area. The fluorescence changes in the above three operations were also offered as movies (Video $1-2$ in SI). Thus TP- $\mathrm{NO}_{2}$ can be better used for intraoperative imaging to guide tumor resection after attaching the targeting group. And we can initially evaluate the efficacy of tumor treatment by NTR imaging.

Then we evaluated the therapeutic effect of HBO-assistant chemotherapy through hematoxylin and eosin (H\&E) staining and terminal deoxynucleotidyl transferase-mediated deoxyuridine triphosphate nick end labeling (TUNEL) staining. As shown in Fig. 5b, we directly observed cell morphology using H\&E. We observed that most cells in the control group had irregular nuclei, which showed the structure of severe malignancy. From the morphological observation, we also observed damaged malignant tumor in the treatment group. TUNEL staining was an indicator of cellular apoptosis, which can point out the cleaved DNA in the nucleus. [45] As shown in Fig. 5c, we observed a small number of cells with nuclei stained in the control group. However, the number of cells with nuclei stained was increased in the HBO- 


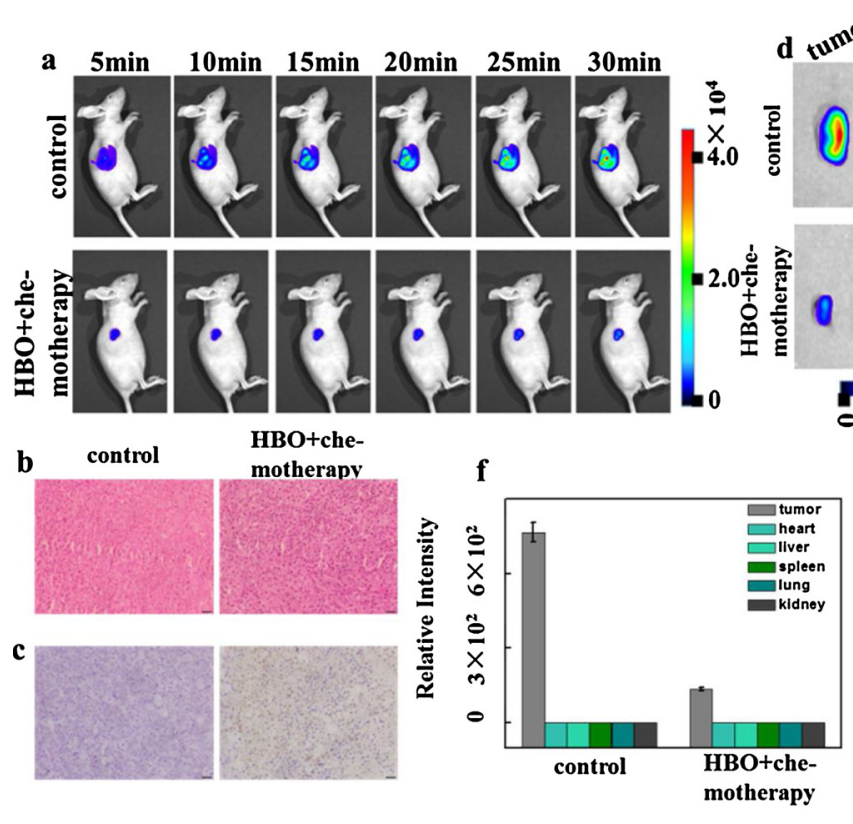

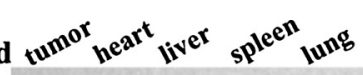
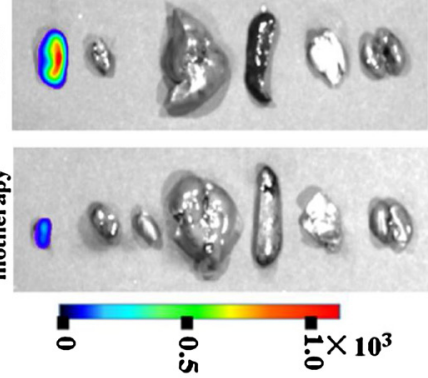

g

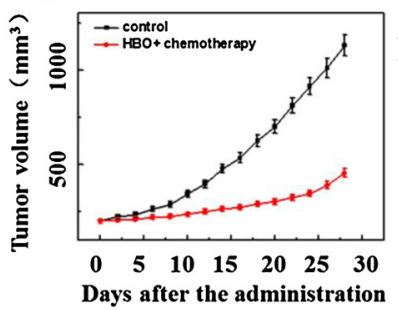

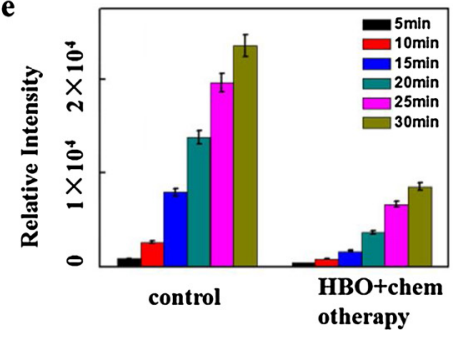

h

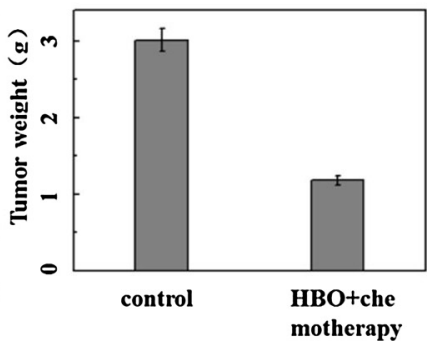

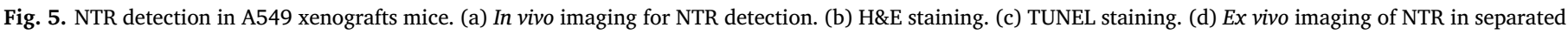

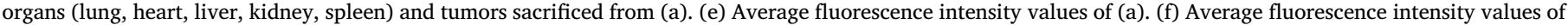

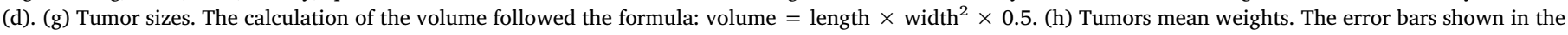
figures represented the mean \pm s.d.

assistant chemotherapy group. These results demonstrated that HBOassistant chemotherapy was an ideal strategy for tumors treatment. In addition, we measured tumor volume and tumor weight to more intuitively observe the effect of tumor treatment (Fig. $5 \mathrm{~g}$ and h). Compared to the tumor in the control group, the tumor volumes in the treatment groups became smaller. Tumor weight was also reduced in the treatment groups compared to tumors in the control group. The mice weight was also recorded, and the results were shown in Figure S10. These results manifested that HBO-assistant chemotherapy can effectively treat tumors and decrease NTR concentration, which can be attributed to the fact that HBO could alleviate tumor hypoxia and improve the efficacy of G/C. Therefore, we can assess the tumor treatment effect during HBO-assistant chemotherapy through NTR detection.

\subsection{Therapy efficaciy of HBO-assistant chemotherapy in A549/DDP xenografts mice}

Tumor hypoxia, the main feature of solid tumors, will lead tumor cells to resist chemotherapy drugs by regulating the expression of multiple genes and directly reduce the therapeutic effect of tumors, which further causes a huge challenge for tumor treatment. The HBOassistant chemotherapy may be a promising strategy for relieving tumor resistance. We further evaluated the treatment effect of HBO-assistant chemotherapy on the mice models that bearing A549/DDP xenograft by NTR detection (Fig. 6). The mice in Fig. 6a were divided into two groups: control group and HBO-assistant chemotherapy group. As shown in Fig. 6a, d, e and f, we can obtain fluorescence signals only in the tumors. The results of fluorescence imaging indicated that $\mathrm{HBO}$ can decrease NTR concentration, and the fluorescence intensity was lowest in the group that treated with $\mathrm{HBO}$-assistant chemotherapy. The fluorescence changes in the above two operations were also offered as movies (Video 3 - 4 in SI). These results suggested that HBO-assistant chemotherapy can effectively treat tumor, which might be a key point to alleviating tumor resistance. And we can assess the effect of tumor treatment using NTR detection.

We also performed H\&E and TUNEL staining for assessing tumor treatment efficacy by observing tissue damage directly. As shown in
Fig. 6b, there was lots of irregular and abnormal nucleus in the control group, which represented severe malignant tumor tissue. We observed damaged tissue in the HBO-assistant chemotherapy group, which suggested good therapeutic effects of HBO-assistant chemotherapy on A549/DDP bearing nude mice. The TUNEL staining in Fig. 6c illustrated that DNA was cleaved during the process of tumor treatment. Thus HBO-assistant chemotherapy can effectively treat tumor. We can more intuitively observe the effect of tumor treatment by directly detecting tumor volume and tumor weight (Fig. $6 \mathrm{~g}$ and $6 \mathrm{~h}$ ). The mice weights were also recorded and the results were shown in Figure S11. These results demonstrated that the treatment effect in the HBO-assistant chemotherapy group was satisfying, and synergistic therapies can effectively inhibit the growth of tumor lesions. Thus HBO-assistant chemotherapy is a promising strategy for tumor treatment.

\section{Conclusion}

We have designed and synthesized a NTR-activatable fluorescent probe, TP- $\mathrm{NO}_{2}$, for NTR detection. TP- $\mathrm{NO}_{2}$ with simple synthesis steps and high yield can quantitatively detect NTR in a wide range $(0-20 \mu \mathrm{g}$ / $\mathrm{mL}$ ) with a detection limit of $26 \mathrm{ng} / \mathrm{mL}$. The fluorescent probe, $\mathrm{TP}-\mathrm{NO}_{2}$, had long emission wavelength and deep tissue imaging depth. The probe was applied for NTR detection in A549 and A549/DDP cells successfully. Furthermore, $\mathrm{HBO}$ can greatly increase intracellular oxygen concentration and decrease the concentration of NTR. Then we applied TP- $\mathrm{NO}_{2}$ for NTR detection in A549 and A549/DDP xenografts mice. The results demonstrated that HBO-assistant chemotherapy can effectively treat tumors. HBO-assisted chemotherapy can significantly reduce the NTR concentration, and TP- $\mathrm{NO}_{2}$ can be used as a promising tool for clinical surgery pre-evaluation during HBO-assistant chemotherapy. We believe that the next probe can be better for intraoperative imaging after attaching tumor-targeting group in the future work. And the strategy we proposed provides a novel perspective in accurate diagnosis and efficacy evaluation of tumor treatment. 

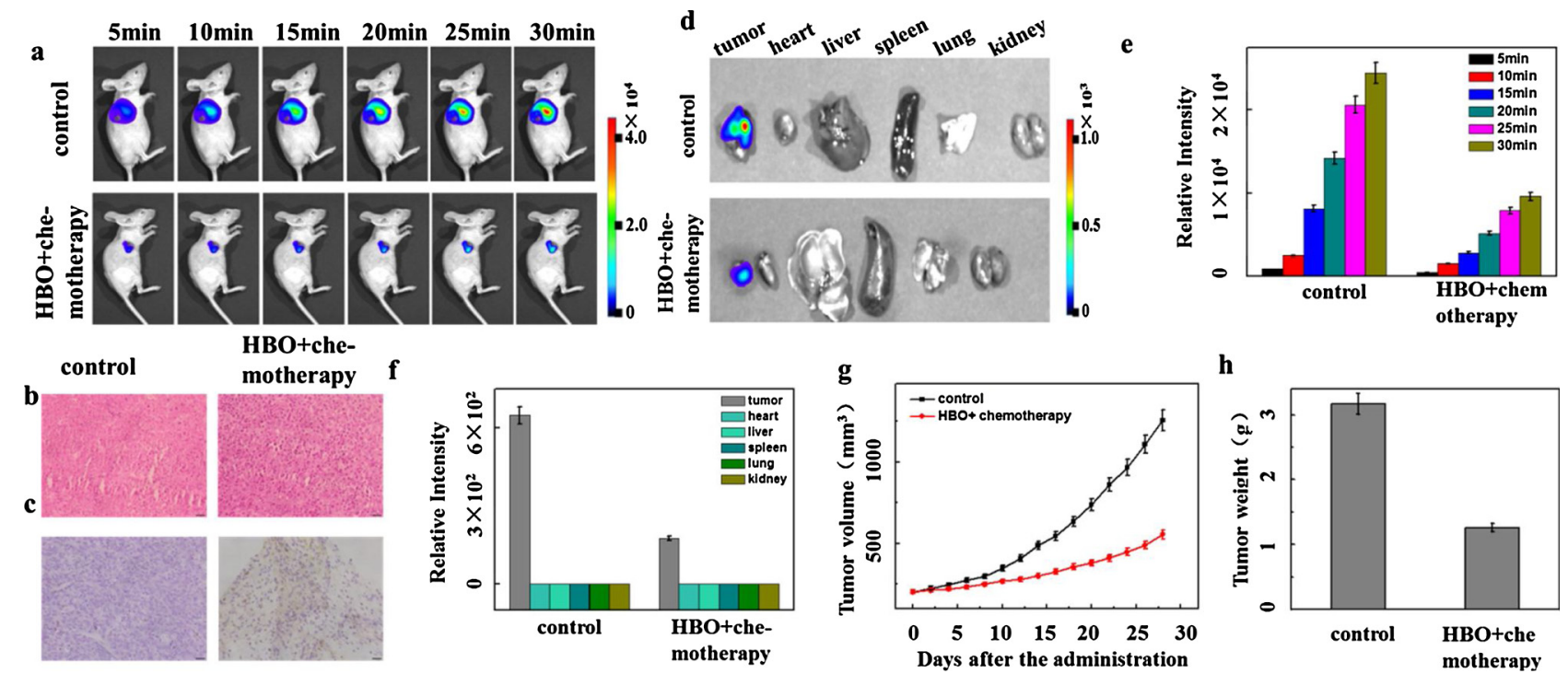

Fig. 6. NTR detection in A549/DDP xenografts mice. (a) NTR detection in vivo. (b) H\&E staining. (c) TUNEL staining. (d) NTR detection in separated organs (lung, heart, liver, kidney, spleen) and tumors sacrificed from (a). (e) Data analysis for (a). (f) Data analysis for (d). (g) Tumor sizes. The calculation of the volume followed the formula: volume $=$ length $\times$ width $2 \times 0.5$. (h) Tumors mean weights. The error bars shown in the figures represented the mean \pm s.d.

\section{Declaration of Competing Interest}

The authors declare no competing financial interest.

\section{Acknowledgments}

We thank the National Nature Science Foundation of China (Nos. 21976209, 21778026), the program of Youth Innovation Promotion Association, CAS (Grant 2019217), and the Taishan Scholar Project Special Funding (No.ts20190962).

\section{Appendix A. Supplementary data}

Supplementary material related to this article can be found, in the online version, at doi:https://doi.org/10.1016/j.snb.2020.127755.

\section{References}

[1] J. Martin Brown, R. Wilson William, Exploiting tumour hypoxia in cancer treatment, Nat. Rev. Cancer 4 (2004) 437.

[2] H. Michael, P. Vaupel, Tumor hypoxia: definitions and current clinical, biologic, and molecular aspects, J. Natl. Cancer. I 93 (2001) 266.

[3] K. Zhu, T. Qin, C. Zhao, Z. Luo, B. Liu, L. Wang, A novel fluorescent turn-on probe for highly selective detection of nitroreductase in tumor cells, Sens. Actuat. B-Chem. 276 (2018) 3973.

[4] J. Zheng, Y. Shen, Z. Xu, Z. Yuan, Y. He, C. Wei, H. Chen, Near-infrared off-on fluorescence probe activated by NTR for in vivo hypoxia imaging, Biosens. Bioelectron. 119 (2018) 141.

[5] G.L. Semenza, Signal transduction to hypoxia-inducible factor 1, Biochem. Pharmacol. 64 (2002) 993.

[6] S.W. Kim, I.K. Kim, J.H. Ha, C.D. Yeo, H.H. Kang, J.W. Kim, S.H. Lee, Normobaric hyperoxia inhibits the progression of lung cancer by inducing apoptosis, Exp. Biol. Med. 243 (2018) 739.

[7] Y. Wang, Y. Qi, X. Wei, S. Chen, N. Jia, Q. Zhou, Y. Wang, Hyperbaric oxygen rescues lung cancer cells from chemical hypoxia-induced low differentiation and apoptosis resistance, Exp. Lung Res. 44 (2018) 417.

[8] K. Selvendiran, M.L. Kuppusamy, S. Ahmed, A. Bratasz, G. Meenakshisundaram, B.K. Rivera, P. Kuppusamy, Oxygenation inhibits ovarian tumor growth by down regulating STAT3 and cyclin-D1 expressions, Cancer. Boil. Ther. 10 (2010) 386.

[9] I. Moen, K.J. Tronstad, O. Kolmannskog, G.S. Salvesen, R.K. Reed, L.E. Stuhr, Hyperoxia increases the uptake of 5-fluorouracil in mammary tumors independently of changes in interstitial fluid pressure and tumor stroma, BMC Cancer 9 (2009) 446.

[10] Y. Li, Y. Sun, J. Li, Q. Su, W. Yuan, Y. Dai, F. Li, Ultrasensitive near-infrared fluorescence-enhanced probe for in vivo nitroreductase imaging, J. Am. Chem. Soc. 137 (2015) 6407-6416.

[11] K.H. Gebremedhin, Y. Li, Q. Yao, M. Xiao, F. Gao, J. Fan, X. Peng, Development of a red-light emission hypoxia-sensitive two-photon fluorescent probe for in vivo nitroreductase imaging, J. Mater. Chem. B 7 (2019) 408-414.

[12] Z.R. Liu, Y. Tang, A. Xu, W. Lin, A new fluorescent probe with a large turn-on signal for imaging nitroreductase in tumor cells and tissues by two-photon microscopy, Biosens. Bioelectron. 89 (2017) 853.

[13] K. Okuda, Y. Okabe, T. Kadonosono, T. Ueno, B.G. Youssif, S. Kizaka-Kondoh, H. Nagasawa, 2-Nitroimidazole-tricarbocyanine conjugate as a near-infrared fluorescent probe for in vivo imaging of tumor hypoxia, Bioconjugate. Chem. 23 (2012) 324.

[14] O. De, I. Marques, D. Bonatto, J.A.P. Henriques, Nitroreductases: enzymes with environmental, biotechnological and clinical importance, Reactions 3 (2010).

[15] A.R. Padhani, K.A. Krohn, J.S. Lewis, M. Alber, Imaging oxygenation of human tumours, Eur. Radiol. 17 (2007) 861-872.

[16] C.M. Doll, M. Milosevic, M. Pintilie, R.P. Hill, A.W. Fyles, Estimating hypoxic status in human tumors: a simulation using Eppendorf oxygen probe data in cervical cancer patients, Int. J. Radiat. Oncol. 55 (2003) 1239-1246.

[17] R.P. Mason, H. Shukla, P.P. Antich, In vivo oxygen tension and temperature: simultaneous determination using 19F NMR spectroscopy of perfluorocarbon, Magnet. Reson. Med. 29 (1993) 296-302.

[18] D. Zhao, L. Jiang, R.P. Mason, Measuring changes in tumor oxygenation, Method. Enzymol. 386 (2004) 378-418.

[19] M. Gerling, Y. Zhao, S. Nania, K.J. Norberg, C.S. Verbeke, B. Englert, R.V. Kuiper, A. Bergström, M. Hassan, A. Neesse, J.M. Löhr, R.L. Heuchel, Real-time assessment of tissue hypoxia in vivo with combined photoacoustics and high-frequency ultrasound, Theranostics 4 (2014) 604-613.

[20] J. Sun, Z. Hu, R. Wang, S. Zhang, X. Zhang, A highly sensitive chemiluminescent probe for detecting nitroreductase and imaging in living animals, Anal. Chem. 91 (2018) 1384-1390

[21] J. Zhang, H.W. Liu, X.X. Hu, J. Li, L.H. Liang, X.B. Zhang, W. Tan, Efficient twophoton fluorescent probe for nitroreductase detection and hypoxia imaging in tumor cells and tissues, Anal. Chem. 87 (2015) 11832-11839.

[22] P. Feng, H. Zhang, Q. Deng, W. Liu, L. Yang, G. Li, M. Li, Real-time bioluminescence imaging of nitroreductase in mouse model, Anal. Chem. 88 (2016) 5610-5614.

[23] A. Xu, Y. Tang, Y. Ma, G. Xu, S. Gao, Y. Zhao, W. Lin, A fast-responsive two-photon fluorescent turn-on probe for nitroreductase and its bioimaging application in living tissues, Sens. Actuat. B-Chem. 252 (2017) 927-933.

[24] Z.R. Liu, Y. Tang, A. Xu, W. Lin, A new fluorescent probe with a large turn-on signal for imaging nitroreductase in tumor cells and tissues by two-photon microscopy, Biosens. Bioelectron. 89 (2017) 853-858.

[25] B. Zhai, W. Hu, J. Sun, S. Chi, Y. Lei, F. Zhang, Z. Liu, A two-photon fluorescent probe for nitroreductase imaging in living cells, tissues and zebrafish under hypoxia conditions, Analyst 142 (2017) 1545-1553.

[26] A. Chevalier, Y. Zhang, O.M. Khdour, J.B. Kaye, S.M. Hecht, Mitochondrial nitroreductase activity enables selective imaging and therapeutic targeting, J. Am. Chem. Soc. 138 (2016) 12009-12012.

[27] Z.R. Liu, Y. Tang, A. Xu, W. Lin, A new fluorescent probe with a large turn-on signal for imaging nitroreductase in tumor cells and tissues by two-photon microscopy, Biosens. Bioelectron. 89 (2017) 853-858.

[28] G. Liu, D. Liu, X. Han, X. Sheng, Z. Xu, S.H. Liu, J. Yin, A hemicyanine-based colorimetric and ratiometric fluorescent probe for selective detection of cysteine and bioimaging in living cell, Talanta 170 (2017) 406-412.

[29] R.K. Jain, Antiangiogenesis strategies revisited: from starving tumors to alleviating hypoxia, Cancer Cell 26 (2014) 605-622.

[30] P. Wardman, E.D. Clarke, Oxygen inhibition of nitroreductase: electron transfer from nitro radical-anions to oxygen, Biochem. Biophys. Res. Co. 69 (1976) 
942-949.

[31] S. Gesto D, M.F.S.A. Cerqueira N, A. Fernandes, P. Gemcitabine, A critical nucleoside for cancer therapy, Curr. Med. Chem. 19 (2012) 1076-1087.

[32] X. Han, X. Song, F. Yu, L. Chen, A ratiometric fluorescent probe for imaging and quantifying anti-apoptotic effects of GSH under temperature stress, Chem. Sci. 8 (2017) 6991-7002.

[33] R.K. Jain, Antiangiogenesis strategies revisited: from starving tumors to alleviating hypoxia, Cancer Cell 26 (2014) 605-622.

[34] P. Nicotera, G. Bellomo, S. Orrenius, Calcium-mediated mechanisms in chemically induced cell death, Annu. Rev. Pharmacol. 32 (1992) 449-470.

[35] Y. Kirichok, G. Krapivinsky, D.E. Clapham, The mitochondrial calcium uniporter is a highly selective ion channel, Nature 427 (2004) 360.

[36] J. Wang, J. Kou, X. Hou, Z. Zhao, H. Chao, A ruthenium (II) anthraquinone complex as the theranostic agent combining hypoxia imaging and HIF-1 $\alpha$ inhibition, Inorg. Chim. Acta Rev. 454 (2017) 176-183.

[37] K. Bartels, A. Grenz, H.K. Eltzschig, Hypoxia and inflammation are two sides of the same coin, Proc. Natl. Acad. Sci. U. S. A. 110 (2013) 18351-18352.

[38] N.A. Belikova, Y.A. Vladimirov, A.N. Osipov, A.A. Kapralov, V.A. Tyurin, M.V. Potapovich, V.E. Kagan, Peroxidase activity and structural transitions of cytochrome c bound to cardiolipin-containing membranes, Biochemistry 45 (2006) 4998-5009.

[39] A.H. Boulares, A.G. Yakovlev, V. Ivanova, B.A. Stoica, G. Wang, S. Iyer, M. Smulson, Role of poly (ADP-ribose) polymerase (PARP) cleavage in apoptosis Caspase 3-resistant PARP mutant increases rates of apoptosis in transfected cells, J. Biol. Chem. 274 (1999) 22932-22940.

[40] A.G. Porter, R.U. Jänicke, Emerging roles of caspase-3 in apoptosis, Cell Death Differ. 6 (1999) 99.

[41] D.B. Zamble, S.J. Lippard, Cisplatin and DNA repair in cancer chemotherapy, Trends Biochem. Sci. 20 (1995) 435-439.

[42] P. Jordan, M. Carmo-Fonseca, Molecular mechanisms involved in cisplatin cytotoxicity, Cell. Mol. Life Sci. 57 (2000) 1229-1235.

[43] D.M. Katschinski, K. Boos, S.G. Schindler, J. Fandrey, Pivotal role of reactive oxygen species as intracellular mediators of hyperthermia-induced apoptosis, J. Biol. Chem. 275 (2000) 21094-21098.

[44] R.E. Johnson, A.R. Kagan, T.L. Bryant, Hyperbaric oxygen effect on experimental tumor growth, Radiology 88 (1967) 775-777.

[45] C. Mantis, I. Kandela, F. Aird, Replication study: coadministration of a tumor-penetrating peptide enhances the efficacy of cancer drugs, Elife (2017) 17584.

[46] Z. Li, X. He, Z. Wang, R. Yang, W. Shi, H. Ma, In vivo imaging and detection of nitroreductase in zebrafish by a new near-infrared fluorescence off-on probe, Biosens. Bioelectron. 63 (2015) 112-116.

[47] Y. Fan, M. Lu, X.A. Yu, M. He, Y. Zhang, X. Ma, J. Tian, Targeted myocardial hypoxia imaging using a nitroreductase-activatable near-infrared fluorescent nanoprobe, Anal. Chem. 91 (2019) 6585-6592.

[48] W. Qin, C. Xu, Y. Zhao, C. Yu, S. Shen, L. Li, W. Huang, Recent progress in small molecule fluorescent probes for nitroreductase, Chin. Chem. Lett. 29 (2018) 1451-1455.

[49] G.F. Sousa, S.R. Wlodarczyk, G. Monteiro, Carboplatin: molecular mechanisms of action associated with chemoresistance, Braz. J. Pharm. Sci. 50 (2014) 693-701.

[50] X. Liu, J. Wang, G. Li, H. Lv, Effect of combined chondroitinase ABC and hyperbaric oxygen therapy in a rat model of spinal cord injury, Mol. Med. Rep. 18 (2018) $25-30$.

[51] Z. Liu, F. Song, W. Shi, G. Gurzadyan, H. Yin, B. Song, X. Peng, Nitroreductaseactivatable theranostic molecules with high PDT efficiency under mild hypoxia based on a TADF fluorescein derivative, ACS Appl. Mater. Inter 11 (2019) 15426-15435.

[52] X. Kong, L. Di, Y. Fan, Z. Zhou, X. Feng, L. Gai, H. Lu, Lysosome-targeting turn-on red/NIR BODIPY probes for imaging hypoxic cells, Chem. Commun. 55 (2019) 11567-11570.

Yue Wang is currently a doctoral candidate, under the guidance of Prof. Lingxin Chen, at Yantai Institute of Coastal Zone Research, Chinese Academy of Sciences, and has been since 2015. She received her BS from Qufu Normal University, in 2015. Her current research interests focus on the development of functional fluorescent probes for bioimaging.

Li Zhang is currently a master candidate, under the guidance of Prof. Lingxin Chen, at Yantai Institute of Coastal Zone Research, Chinese Academy of Sciences, and has been since 2019. She received her BS from Qingdao University of Science and Technology, in 2019. Her current research interests focus on the development of functional fluorescent probes for bioimaging.

Yan Huang is now an associate professor at School of Pharmacy, Binzhou Medical University. He obtained his Ph.D. in analytical chemistry, joint-educated, at Shandong Normal University, and Yantai Institute of Coastal Zone Research, Chinese Academy of Sciences, since 2016. His research interests focus on functional fluorescent probe, theranostics, and functional nanomaterial.

Xiaoyan Wang is now an associate professor at School of Pharmacy, Binzhou Medical University. She received her Ph.D. in analytical chemistry, joint-educated, at Shandong Normal University, and Yantai Institute of Coastal Zone Research, Chinese Academy of Sciences, since 2013. Her current research interests focus on the preparation \& application of molecularly imprinted polymers in chromatographic separation and chemical sensors for analysis of typical pollutants and biomacromolecules.

Liangwei Zhang is now He is now an associate professor at Yantai Institute of Coastal Zone Research, Chinese Academy of Sciences, since 2018. He received his Ph.D. degree at College of Chemistry and Chemical Engineering, Lanzhou University, in 2013. His current research interests include small molecular fluorescent probes for detection of enzymatic activity and biological molecules.

Lingxin Chen has been a professor at Yantai Institute of Coastal Zone Research, Chinese Academy of Sciences, since 2009. He obtained his Ph.D. in analytical chemistry at Dalian Institute of Chemical Physics, Chinese Academy of Sciences, in 2003. During 2004-2009, he worked at Department of Chemistry, Tsinghua University, and Department of Applied Chemistry, Hanyang University, respectively. His research interests include the studies of novel properties of materials such as functionalized nanoparticles \& functional probe molecules for developing nanoscale biochemical analysis methods and molecular imprinting-based sample pretreatment technology. 